\title{
Listening to the landscape of our cities
}

\author{
R. Balanzó \\ Department of Design and Space, \\ Fundació Escola Universitària Elisava, University Pompeu Fabra, \\ Barcelona, Spain
}

\begin{abstract}
The tyranny of architecture and urbanism, made without a participatory design with inhabitants, and the adjectival use of the space combined with the imposition of economic and functional factors have become the sign of times that strongly affect the evolution and generation of cities. Where have the diversity, complexity, and mixture of the urban ecosystem gone?

We must flee from the premises of the Charte d'Athènes and progress towards the creation of a city rich in multicultural and ecological diversity. For this purpose, this paper proposes to rethink the concept of the city starting from the already existent natural and social landscaping. More specifically, this paper recommends listening to the landscape in the conception of our cities and claims its incorporation as a representative element into the creation of the neighbourhoods.

We propose that the city metamorphoses into an eco-urban system and becomes the succession of void spaces, a poetical landscape that would be enriched by the personal and private experiences of its inhabitants. Far from being the unique and lonely conception of the artist, the architect and the landscape architect, the city would become a common space, the symbiosis between the creators and the inhabitants joined by the mutual desire of sharing personal experiences. Moreover, these designed urban landscapes shall transform the city into a more balanced and human space that facilitates contemplation and sustainable growth. We will analyse two different case studies, the first a new eco-neigborhood in an old industrial land in central Europe, and the second case study a new park in the existing city in the Mediterranean coast.
\end{abstract}

Keywords: architecture, landscape, sustainable, eco-city, nature, bioclimatic. 


\section{Introduction}

"Le paysagisme, lui, est holiste de naissance et lorsque l'architecture s'y fond, elle devient aussitôt outil de la civilisation" [1].

During a workshop on designing landscape, we were asked to choose and symbolically represent one of the cities described in Italo Calvino's book [1], [2]. After selecting the city in the chapter, "The tenues cities 5", we used both drawings and sculptures to describe our preconscious thoughts and feelings about this city. In the process of completing this exercise, we realized that somewhere in the city that we had created there were a series of spaces and landscapes that represented the risk, the transgression, the order, and the chaos. The spaces were a combination of the following features: crossing boundaries, transition, procession, celebration, arrival, departure, spiritualism, symbolism, poetry, growth, decay, security, instability, freedom, tranquillity, and beauty.

This workshop made us realize that the landscape has the power to: broadcast our emotions, represent the temporality and evolution of nature and symbolize the self-sufficient ecosystem that we must adapt to our urban system in order to generate economically, socially and environmentally sustainable cities and neighbourhoods. Land Art in the 1970s was a proposal to symbolise the human emotions in a symbiosis with nature and earth.

\section{The language of the landscape - first case study: La Louvière, the reconversation of an industrial site to an urban regeneration with a mixed neighbourhood}

\subsection{The landscape as the origin}

Our proposal for creating a sustainable neighbourhood in La Louvière, Belgium, emerges from our analysis of the landscape in the region, and considers both its conditions and its potentials. In particular, we identified that the layers had a key role in the landscape, as described below:

\subsection{The undulating landscape of the place and the social context}

The spectacular hills of carbon were the result of years of mining that had generated artificial mountains and metamorphosed the topography. A new landscape, a new social layer. A landscape of a second generation, in which the artificial became the art of the landscape. Hills of minerals extracted from the depths of the earth. The profound made visible, the presence of the hidden.

\subsection{The characteristics of the vegetation and the bioclimatic and environmental aspects}

La Louvière is characterised by a natural landscaping that superposes hills and forests. Moreover, the organic richness of the hills of minerals and the new topography with south orientation enhance the vegetation growth. 


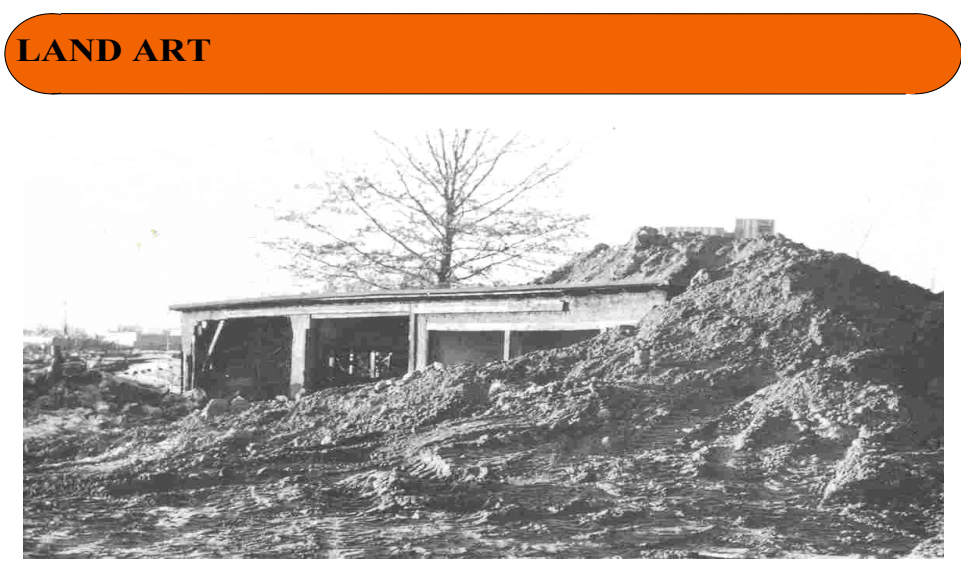

Partially Buried Woodsheed, Robert Smithson, 1970

Figure 1: A workshop conference of Land Art in USA.

Table 1: $\quad$ Eco-urban methodology.

\begin{tabular}{|l|l|l|}
\hline Original landscape & Architecture & Landscape synthesis \\
\hline Boundaries & & \\
Mineral hills & Orientation & Social ecology \\
Lots of land & Recycling & Eco-agricultural \\
\hline
\end{tabular}

\subsection{The landscape as the function}

The objective of the case study is to create of a "landscape synthesis", that is, we propose to rethink the concept of the city, La Louvière, starting from the already existent natural and social landscaping. We thus aim to create new structures that can value La Louvière's natural potential. For this purpose, we shall use the methodology summarized in Table 1. This methodology synthesizes the precepts of urban design, ecology and architecture to enhance the social and ecological values of the urban ecosystem.

It is important to note that this methodology contrasts with the more standard approach, which we do not recommend, that considers the houses as simple and independent objects spread out in the landscape. This approach would lead to a superposition of houses with their own lots of land, and would reduce the environment into another object. 
Alternatively, our proposal listens to the landscape of La Louvière and claims

its incorporation as a representative element of this city. The idea being that simultaneously with the creation of urban space, we shall create the landscape. For example, we propose to distribute the housing units on an undulating topography creating an intertwined relationship between constructed and natural spaces, and shying away from the pseudo-natural spaces that juxtapose houses and their lots together. Our approach implies that houses are surrounded by nature that changes and varies with time and weather.

A new urban landscape designed between the creators and the inhabitants joint by the mutual desire of sharing the personal experiences. Moreover, these projected gardens shall transform the city into a more balanced and human space that facilitates contemplation and sustainable growth as shown in fig. 2.

\section{The language of the Mediterranean Landscape - second case study: Tres turons hills in Barcelona and how to regenerate a 1950s growing urban structure to a new mixed park}

\subsection{The Mediterranean landscape as the origin}

Our proposal for creating a sustainable neighbourhood emerges from our analysis of the landscape in the region, and considers both its conditions and its potentials.

In particular, we identified that the layers had a key role in the landscape, as described below.

\subsection{The Mediterranean landscape and the social context}

Barcelona is characterised by a natural landscaping that superposes hills and city. Moreover, the organic richness of the hills and the topography with south orientation enhance the vegetation growth with traditional system of using raining water. In the park güell in Barcelona, the architect Gaudí thought about how urban design lead an eco-sufficient, and less consumption of water. This design give us an traditional strategy to control water speed that circulated on a inclinated ground with a rocky substratum, and this an essential aspect in order to avoid its erosion and to allow it the fertilization of the land, to the formation of the ground and the process will lead to the growing vegetation onto the hard Gaudi architecture.

\subsection{The Mediterranean landscape as the function}

The objective of this second case study is to re-create of a "landscape synthesis", that is, we propose to rethink the concept of the city of Barcelona starting from the already existent natural and social landscaping. We propose the same methodology but in another context but maintaining the precepts sustainability in landscape and city design to enhance the social network. 


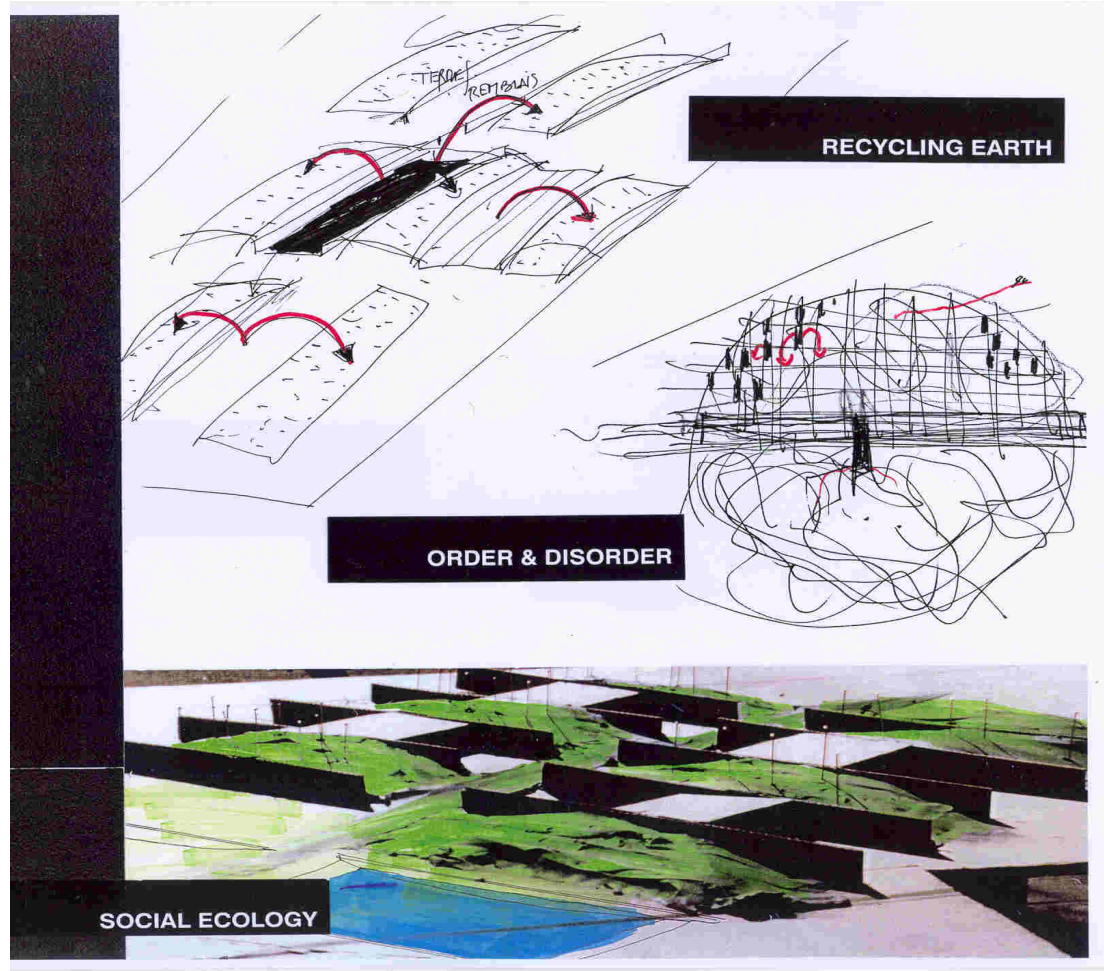

Figure 2: Social neighbourhood units. Social Ecology.

\section{LANDSCAPE $<=>$ ARCHITECTURE}
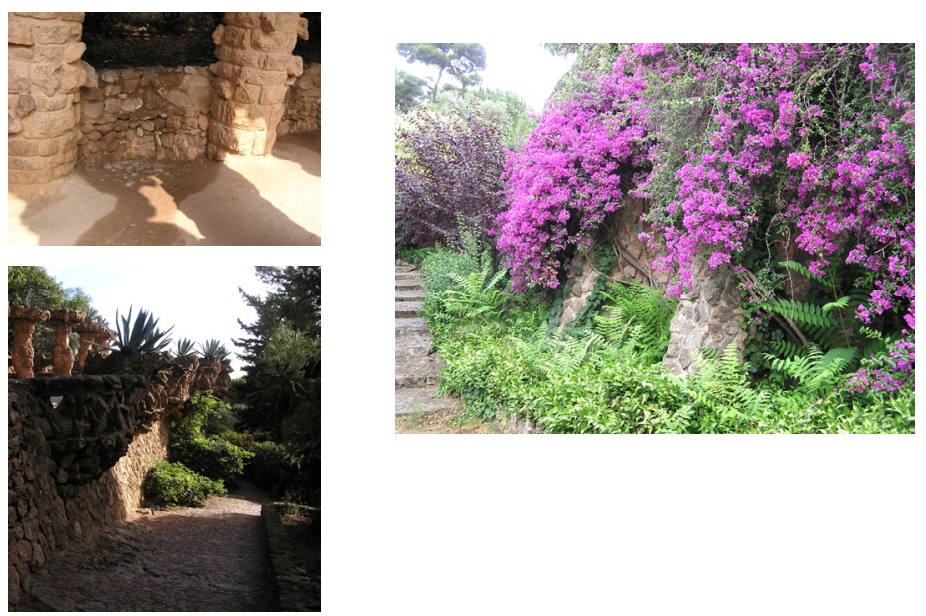

Figure 3: $\quad$ Park Güell, 1912 Antoni Gaudi. 


\section{SECOND CASE STUDY: PARK OF TRES TURONS, BARCELONA}
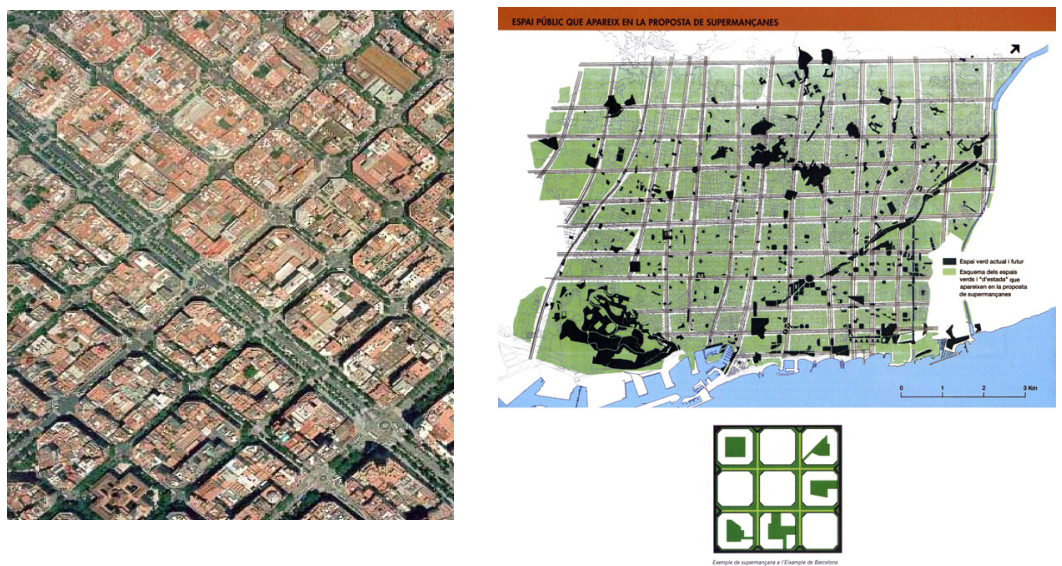

Agenda $21 \mathrm{BCN} 8 / 10$

Figure 4.

\section{TWO PROPOSALS: \\ CITY COUNCIL VERSUS INHABITANTS}
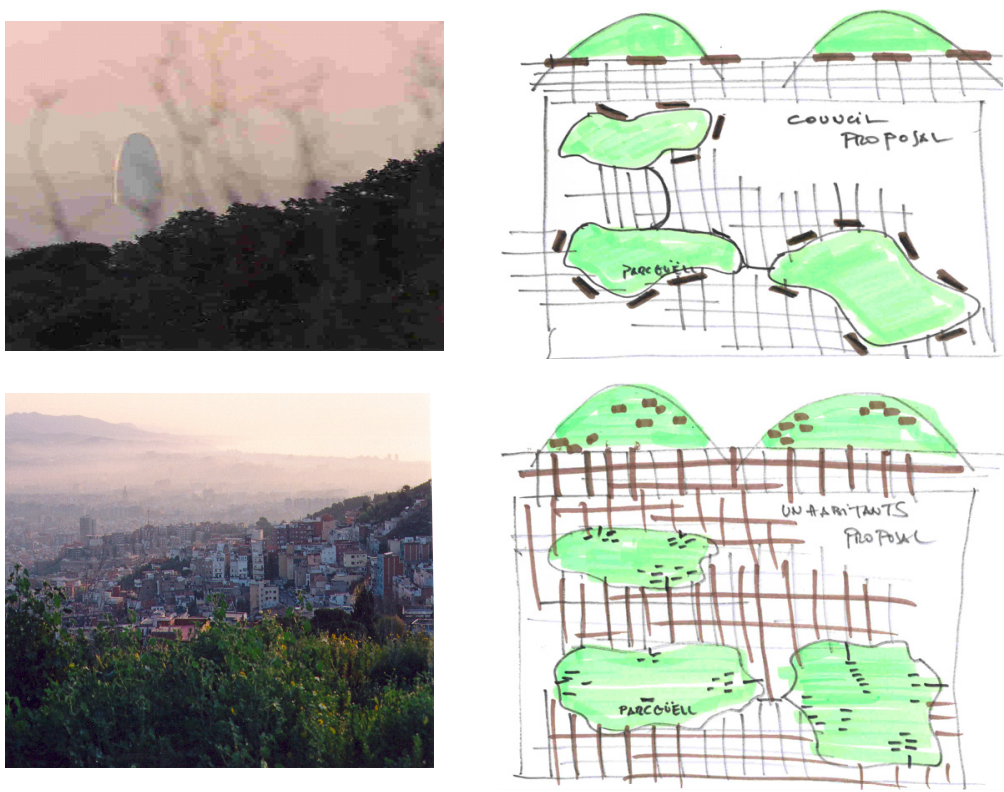

Figure 5. 
The idea is to preserve the existing park with the inhabitants, to lead a new process between people and nature to create an eco-neighbourhood, to reinforce the boundaries between Mediterranean landscape and society. The results will be to integrate in this project the use of the natural cycles of primary resources (rainwater, earth, mezzo-clima, waste) in the existing urban tissue, and to generate landscape for an auto-sufficient urban eco-system and patterns for high social usability.

Like the EC green paper, the project of landscape of Tres Turons has to manage as the best example of sustainable urban values like compactness, mix of land use, sustainable mobility, soft and calming urbanism, strive for high daily, seasonal, and annual outdoor comfort, provide oarchs for liveability, legibility and connectivity of public space patterns, minimise noise and air pollution, etc and create landscape patterns for high social usability.

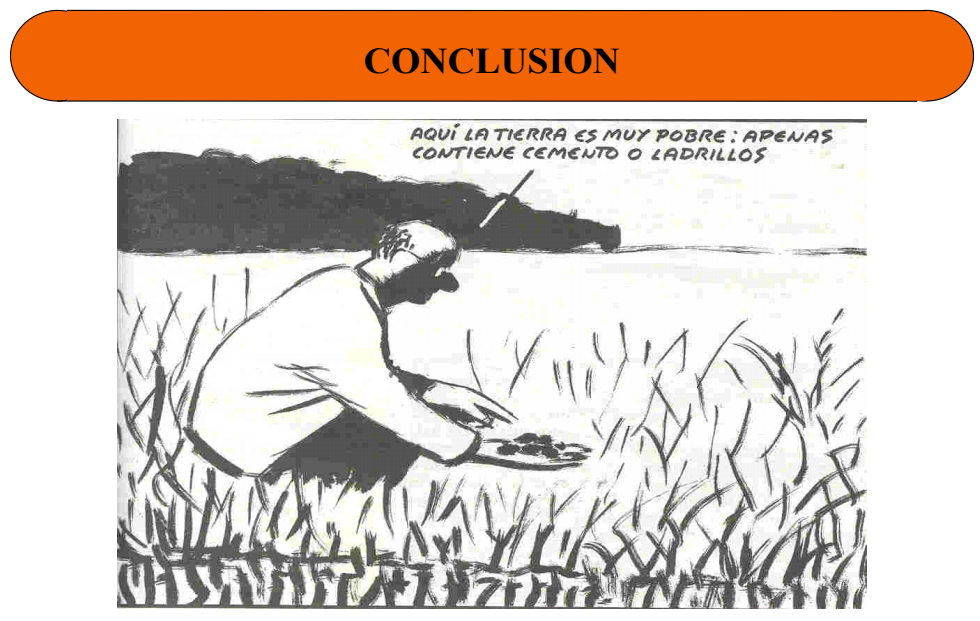

This landscape is poor, it lacks of concrete, and bricks.

Figure 6.

\section{Conclusion}

How we have seen in the two different studies cases, we propose a new methodology to redesign neighbourhoods in a existing network of an industrial city, urban landscape with his environmental, economical, and social functions could be the catalyser to create an eco-city. Nowadays there is a big effort from politics, technical teams, and inhabitants into designing sustainable spaces using low-consumption fluxes of materials, and take advantage of the existing natural eco-systems and the existing social networks to create a real eco-urban landscape and reinforce the symbiosis between culture and nature. 
820 Sustainable Development and Planning III

\section{References}

[1] Kroll, L. Tout est paysage, Sens \& tonka, Paris, 2001

[2] Calvino, I. Le citta invisibili, Giulio Einaudi, Roma, 1972

[3] Calvino, I. Marcovaldo o sea las estaciones de la ciudad, Giulio Einaudi, Roma , 1973 